Document downloaded from:

http://hdl.handle.net/10251/150640

This paper must be cited as:

Tello, J.; Cubero, S.; Blasco Ivars, J.; Tardaguila, J.; Aleixos Borrás, MN.; Ibanez, J. (2016). Application of 2D and 3D image technologies to characterize morphological attributes of grapevine clusters. Journal of the Science of Food and Agriculture. 96:4575-4583. https://doi.org/10.1002/jsfa.7675

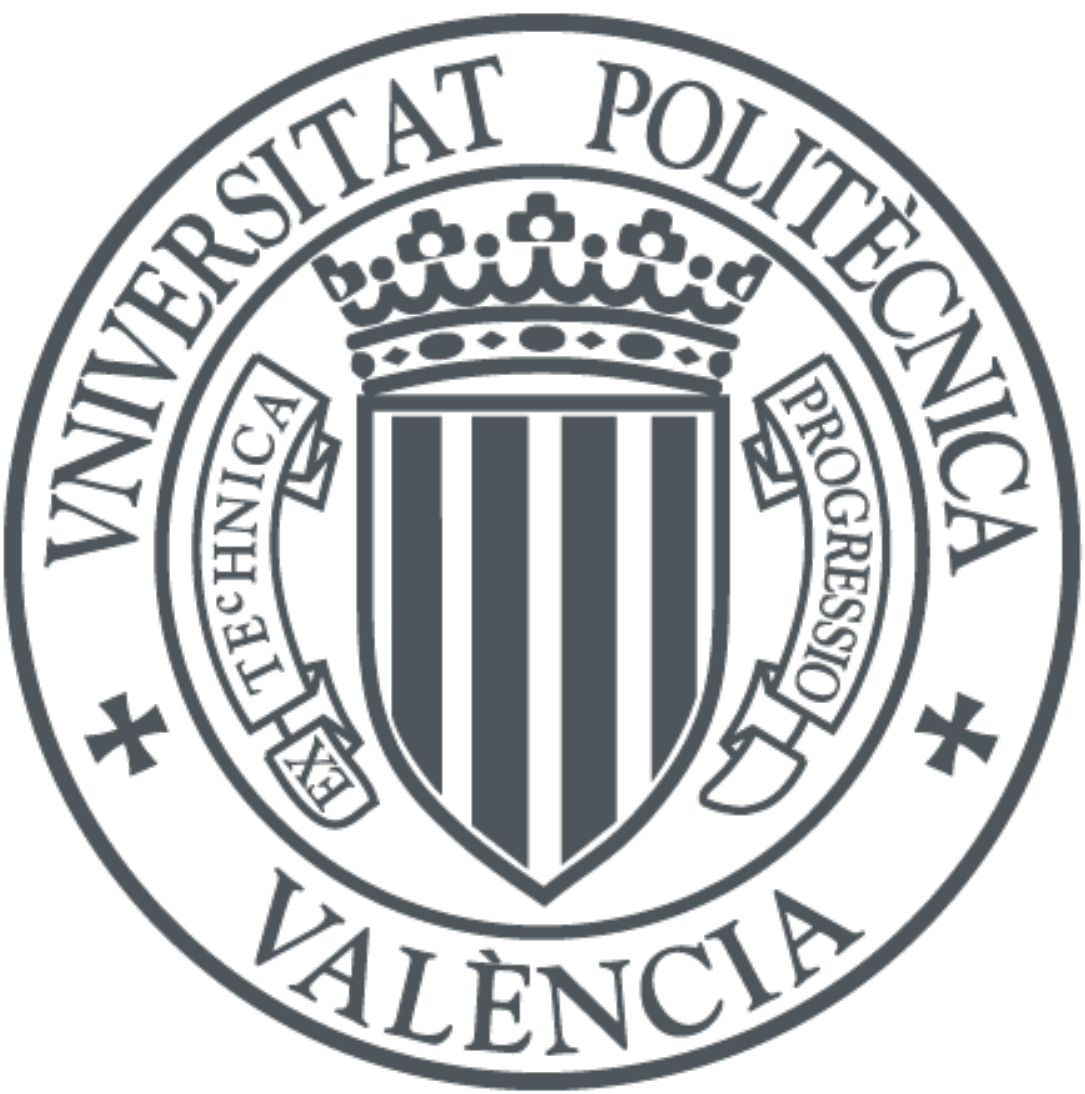

The final publication is available at

https://doi.org/10.1002/jsfa.7675

Copyright John Wiley \& Sons

Additional Information 


\title{
Application of 2D and 3D image technologies to characterize morphological attributes of grapevine clusters
}

Javier Tello ${ }^{a}$, Sergio Cubero ${ }^{a, b}$, José Blasco ${ }^{b}$, Javier Tardaguila ${ }^{a}$, Nuria Aleixos ${ }^{c}$, Javier Ibáñez ${ }^{\mathrm{a}^{*}}$

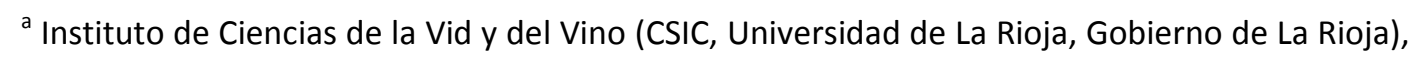
Logroño, Spain

${ }^{\text {b }}$ Centro de Agroingeniería, Instituto Valenciano de Investigaciones Agrarias (IVIA), Moncada, Spain

${ }^{c}$ Departamento de Ingeniería Gráfica. Universitat Politècnica de València, Valencia, Spain

*Corresponding author: Javier Ibáñez. Tel.: +34 941894 980; fax: +34 941899 728. E-mail address: javier.ibanez@icvv.es

\begin{abstract}
BACKGROUND: Grapevine cluster morphology influences the quality and commercial value of wine and table grapes. It is routinely evaluated by subjective and inaccurate methods that do not meet the requirements set by the food industry. Novel 2D and $3 \mathrm{D}$ machine vision technologies emerge as promising tools for its automatic and fast evaluation.
\end{abstract}

This article has been accepted for publication and undergone full peer review but has not been through the copyediting, typesetting, pagination and proofreading process, which may lead to differences between this version and the Version of Record. Please cite this article as doi: $10.1002 /$ jsfa.7675

This article is protected by copyright. All rights reserved. 
RESULTS: The automatic evaluation of cluster length, width and elongation was successfully achieved by the analysis of 2D images, significant and strong correlations with the manual methods being found ( $r=0.959,0.861$ and 0.852 , respectively). The classification of clusters according to their shape can be achieved by evaluating their conicity in different sections of the cluster. The geometric reconstruction of the morphological volume of the cluster from 2D features worked better than the direct 3D laser scanning system, showing a high correlation ( $r=0.956)$ with the manual approach (water displacement method). In addition, we constructed and validated a simple linear regression model for cluster compactness estimation. It showed a high predictive capacity for both the training and validation subsets of clusters $\left(R^{2}=84.5\right.$ and $71.1 \%$, respectively).

CONCLUSION: The methodologies proposed in this work provide continuous and accurate data for the fast objective characterization of cluster morphology.

Keywords: Vitis vinifera L., cluster size, cluster compactness, cluster shape, machine vision

\section{INTRODUCTION}

Grapevine (Vitis vinifera L.) is considered to be the most valuable horticultural crop in the world, mainly grown for the transformation of grapes into wine and raisins, and for their direct consumption as fresh fruit. The quality, acceptability and further commercialization of grapevine clusters depend on many aspects, including diverse morphological (e.g., cluster size or compactness), physical-chemical (e.g., concentration of sugars and acids) and sanitary factors (e.g., presence of rotten berries) ${ }^{1}$. Cluster morphology is determined by several attributes (like cluster size, shape, elongation and compactness) that affect its appearance, which is especially relevant for the table grape market ${ }^{1}$. Such attributes also influence the industrial processing of grapes, with large clusters requiring hand trimming to fit packaging ${ }^{2}$, which increases production costs. On the other hand, cluster selection is becoming a common practice at some wineries for selecting high quality fruits to produce premium wines ${ }^{3}$. In this

This article is protected by copyright. All rights reserved. 
light, winemakers usually reject highly compact clusters, which are considered of lower quality $^{4-8}$. Cluster size, shape and compactness are routinely evaluated by visual methods, like those proposed by the International Organization of Vine and Wine (O.I.V.) $)^{9}$. These approaches often do not satisfy the requirements set by the food industry and breeding programs, which demand fast, non-destructive, objective and accurate techniques to screen a large number of samples in a short period of time $\mathrm{e}^{10-12}$.

The grapevine cluster is a branched structure, composed of a number of ramifications of different lengths. Each ramification comprises a highly variable number of berries, whose size and shape also vary widely ${ }^{2,7,13}$. This singular structure means two different volumes can be considered in the cluster: the actual (or solid) and the morphological (or apparent) one, and cluster compactness is determined by the difference between them ${ }^{4,14}$. The actual volume of the cluster is mainly composed of the volume of the berries (the volume of the rachis -or stem- is insignificant), whereas the morphological one is also defined by the way that this solid volume is arranged three-dimensionally ${ }^{4}$. The evaluation of the morphological volume of the cluster is a complex task, since it includes the volume of the berries and the volume existing in the cavities of the cluster. It has been previously evaluated by relatively imprecise, tedious and time-consuming methods, such as filling the cavities with melted paraffin ${ }^{15}$, wrapping the clusters with different plastic systems $s^{10,16}$ or assimilating the cluster to a perfect cone ${ }^{14}$.

Recent advances in computing, robotics and machine vision provide a new framework for the automated and accurate morphological evaluation of different fruits and vegetables ${ }^{17-20}$. Nonetheless, most fruits and vegetables have regular shapes with clearly defined surfaces that facilitate external inspection by machine vision methods. However, the singular morphology of the grapevine fruit makes the evaluation of such attributes through the use of novel imagebased technologies a real challenge.

This article is protected by copyright. All rights reserved. 
In recent years, several works have successfully applied the analysis of $2 \mathrm{D}$ images for the evaluation of cluster attributes and cluster components, like cluster weight ${ }^{21,22}$ or the number of berries per cluster ${ }^{11,21,22}$. Moreover, the dimensions of the berry have also been estimated through the analysis of $2 \mathrm{D}$ images taken under laboratory ${ }^{11,23}$ or field conditions ${ }^{12}$. Recently, a methodology for the acquisition and consequent analysis of 2D images for the extraction of cluster compactness-related attributes has been detailed ${ }^{24}$. Following this work, a model based on seven variables has been proposed as an alternative to the current visual method of estimation. On the other hand, novel 3D technologies emerge as interesting approaches for the evaluation of cluster morphology. In this same line, the 3D reconstruction of the structure of the grapevine cluster from 2D images has also been assayed for the evaluation of different cluster attributes, including cluster compactness ${ }^{25,26}$. Ivorra, Sánchez, Camarasa, Diago and Tardáguila ${ }^{25}$ created a 3D model from only one face of the cluster. On the other hand, 3D laser scanning has recently been used to create more accurate models of full clusters ${ }^{27}$, but it has not yet been applied in a multicultivar framework.

The aim of this work was to apply 2D imaging and 3D scanning to estimate cluster length, width, volume and elongation, and evaluate their accuracy compared to traditional and timeconsuming approaches. Moreover, variables extracted from these novel systems were applied to the objective evaluation of cluster shape and compactness.

\section{MATERIAL AND METHODS}

\section{Plant material}

This study was carried out during the 2011 vintage on eight different grapevine cultivars (Aramon, Bobal, Cabernet Franc, Danugue, Derechero de Muniesa, Monastrell, Moravia Agria and Ruby Seedless), which were previously identified by genetic analysis to assess their distinctness. Grapevines were grown on an experimental plot of the Grapevine Collection of the Instituto de Ciencias de la Vid y del Vino (ICVV; FAO Institute Code: ESP217), located in

This article is protected by copyright. All rights reserved. 
Agoncillo (La Rioja, Spain). Ten mature clusters (21.4 $\pm 2.1^{\circ} \mathrm{Brix}$ ) were collected per cultivar at harvest time, and kept at $4{ }^{\circ} \mathrm{C}$ until their use for 3D scanning, 2D image acquisition, and morphological description (Figure 1).

\section{D scanning}

The process of 3D digitizing the 80 clusters was performed by an external reverse-engineering company (Asorcad, Barcelona, Spain). Clusters were hung from the peduncle so as not to distort their shape, and individually scanned by a portable UNIscan ${ }^{\top \mathrm{M}}$ scanner (Creaform, Leinfelden-Echterdingen, Germany). This generated a cloud of datapoints for each cluster (Figure $2 \mathrm{~A}$ ) that were analyzed with the RAPIDFORM XOS software application (now Geomagic XOS, Rock Hill, SC, USA) in order to model a closed mesh connecting such datapoints to form poly-faces (Figure $1 \mathrm{~B}$ and $2 \mathrm{~B})$. The volume of the closed mesh representing the cluster $\left(\mathrm{MVO}_{3 \mathrm{D}}\right)$ was automatically released by the same software.

\section{D image acquisition and analysis}

Grapevine clusters were placed in front of a camera (EOS 550D, Canon Inc., Tokyo, Japan), hanging from the peduncle to maintain their shape. The camera was placed inside an inspection chamber with a lighting system composed of eight fluorescent tubes (Biolux L18W/965, $6500 \mathrm{~K}$, Osram AG, Munich, Germany) located on the four sides of the chamber. We used a uniform background to facilitate later image processing. Four images with a resolution of $0.12 \mathrm{~mm} /$ pixel were taken per individual, one for each side of the cluster (front, lateral and back sides), after a $90^{\circ}$ rotation between each image acquisition. The resulting 320 images were analyzed as previously described ${ }^{24}$ to obtain an automatic value for cluster maximal length $\left(\mathrm{Le}_{2 \mathrm{D}}\right)$, maximal width $\left(\mathrm{Wi}_{2 \mathrm{D}}\right)$, widths at $25 \%\left(\mathrm{Wi}_{25} 5_{2 \mathrm{D}}\right), 40 \%\left(\mathrm{Wi} 4 \mathrm{O}_{2 \mathrm{D}}\right), 50 \%$ $\left(\mathrm{Wi}_{50} \mathrm{D}_{2 \mathrm{D}}\right), 60 \%\left(\mathrm{Wi} \mathrm{O}_{2 \mathrm{D}}\right), 75 \%\left(\mathrm{Wi}_{2 \mathrm{D}}\right)$ and $80 \%\left(\mathrm{Wi}_{2 \mathrm{D}}\right)$ of the major axis of the cluster, and the percentage of pixels occupied by the rachis $\left(A R_{2 D}\right)$ and empty holes $\left(A H_{2 D}\right)$ per image (Figure 1C). We considered the average value of the four images of the cluster for each

This article is protected by copyright. All rights reserved. 
variable except for the determination of $\mathrm{Wi}_{2 \mathrm{D}}$, which was calculated as the average of the two largest values.

On the basis of these variables, a geometric reconstruction of each cluster was performed to estimate its morphological volume. For the sake of simplicity, clusters were divided into only four sections of equal height $\left(a, b, c\right.$ and $d$ in Figure 1D), considering $\mathrm{Wi}_{2 \mathrm{2}}, \mathrm{Wi}_{2 \mathrm{O}} \mathrm{D}$ and Wi75 2 . Sections $a$ and $d$ were considered to be two perfect cylinders, while sections $b$ and $c$ were defined by the variables $\mathrm{Wi}_{2} 5_{2 \mathrm{D}}$ and $\mathrm{Wi}^{5} \mathrm{O}_{2 \mathrm{D}}$, and $\mathrm{Wi}_{2 \mathrm{D}}$ and $\mathrm{Wi}_{2 \mathrm{D}}$ respectively, ranging from cylinders (when the two widths considered were found to be identical) to truncated cones. Their volumes were estimated according to equations 1 to 4 , and the total morphological volume of the cluster $\left(\mathrm{MVo}_{2 \mathrm{D}}\right)$ was calculated as $\mathrm{V}_{a}+\mathrm{V}_{b}+\mathrm{V}_{c}+\mathrm{V}_{d}$, as previously suggested $^{28}$.

$\mathrm{V}_{\mathrm{a}}=\pi \times\left(\frac{\mathrm{Wi} 25_{2 \mathrm{D}}}{2}\right)^{2} \times \frac{\mathrm{Le}_{2 \mathrm{D}}}{4}$

$V_{b}=\frac{\pi}{3} \times\left[\left(\frac{W i 25_{2 D}}{2}\right)^{2}+\left(\frac{W i 50_{2 D}}{2}\right)^{2}+\left(\frac{W i 25_{2 D}}{2} \times \frac{W i 50_{2 D}}{2}\right)\right] \times \frac{\mathrm{Le}_{2 \mathrm{D}}}{4}$

$V_{c}=\frac{\pi}{3} \times\left[\left(\frac{W_{i 50} \mathrm{D}}{2}\right)^{2}+\left(\frac{\mathrm{Wi}_{75_{2 \mathrm{D}}}}{2}\right)^{2}+\left(\frac{\mathrm{Wi}^{2} 0_{2 \mathrm{D}}}{2} \times \frac{\mathrm{Wi}_{75_{2 \mathrm{D}}}}{2}\right)\right] \times \frac{\mathrm{Le}_{2 \mathrm{D}}}{4}$

$\mathrm{V}_{\mathrm{d}}=\pi \times\left(\frac{\mathrm{WiF5}_{2 \mathrm{D}}}{2}\right)^{2} \times \frac{\mathrm{Le}_{2 \mathrm{D}}}{4}$

Bearing in mind that the visual O.I.V. descriptor № $208^{9}$ for cluster shape evaluates this trait according to the morphology of its central section (between $40 \%$ and $80 \%$ of its main axis), we evaluated the conicity for this section $\left(C_{1}\right)$ and for its lower half $\left(C_{2}\right)$ as promising objective indicators of cluster shape. Conicity was automatically calculated following the ISO Standard 3040:2009 for the dimensioning of cones (www.iso.org), using $\mathrm{Wi}_{2 \mathrm{O}}$ and $\mathrm{Wi}_{2 \mathrm{D}}$, $\left(\mathrm{C}_{1}, \mathrm{Eq} .5\right)$, and $\mathrm{Wi}_{2 \mathrm{D}}$ and $\mathrm{Wi}_{2 \mathrm{D}}\left(\mathrm{C}_{2}\right.$, Eq.6) for its computation.

$\mathrm{C}_{1}=\frac{\mathrm{Wi}_{40} 0_{2 \mathrm{D}}(\mathrm{cm})-\mathrm{Wi} 80_{2 \mathrm{D}}(\mathrm{cm})}{0.4 \times \mathrm{Le}_{2 \mathrm{D}}(\mathrm{cm})}$

This article is protected by copyright. All rights reserved. 
$\mathrm{C}_{2}=\frac{\mathrm{Wi}_{2 \mathrm{D}}(\mathrm{cm})-\mathrm{Wi}_{2 \mathrm{D}}(\mathrm{cm})}{0.2 \times \mathrm{Le}_{2 \mathrm{D}}(\mathrm{cm})}$

On the other hand, we calculated the compactness index $\mathrm{Cl}-13$ proposed by Tello and Ibáñez ${ }^{10}$ (Eq.7), using the values obtained from 2D image analysis.

$\mathrm{CI}-13_{2 \mathrm{D}}=\frac{\mathrm{MVo}_{2 \mathrm{D}}(\mathrm{mL})}{\left[\mathrm{Le}_{2 \mathrm{D}}(\mathrm{cm})\right]^{2}}$

\section{Morphological description of grapevine clusters}

Each cluster was characterized morphologically using quantitative and objective methods. Cluster weight $\left(\mathrm{We}_{\mathrm{m}}\right)$ was determined using a scale (Blauscal AC-5000, Barcelona, Spain), and cluster length $\left(\mathrm{Le}_{\mathrm{m}}\right)$ and width $\left(\mathrm{Wi}_{\mathrm{m}}\right)$ by means of standard rulers following the descriptors № 202 and № 203 proposed by the O.I.V. ${ }^{9}$, respectively. The morphological volume of the cluster $\left(\mathrm{MVo}_{\mathrm{m}}\right)$ was determined using the water displacement method, as described in Tello and Ibáñez ${ }^{10}$. To obtain quantitative and objective values of compactness, the index $\mathrm{Cl}-12^{10}$, based on cluster weight and length, was calculated (Eq.8). Cluster elongation (EI) was estimated according to Eq.9.

$\mathrm{CI}-12=\frac{\mathrm{We}_{\mathrm{m}}(\mathrm{g})}{\left[\mathrm{Le}_{\mathrm{m}}(\mathrm{cm})\right]^{2}}$

$\mathrm{El}=\frac{\mathrm{Le}(\mathrm{cm})}{\mathrm{Wi}(\mathrm{cm})}$

Cluster compactness was also evaluated qualitatively by a panel of 14 trained judges using the O.I.V. descriptor № $204^{9}$, as previously detailed ${ }^{10,24}$, considering the mode value provided by the evaluators for statistical tests. This descriptor classifies grapevine clusters on five levels, from "very loose" (O.I.V. compactness=1) to "very compact" (O.I.V. compactness=9), according to the visibility of the pedicels and the mobility and deformation of the berries. Cluster shape (Sh) was visually evaluated following the O.I.V. descriptor № $208^{9}$ based on the morphology of the central part of the cluster (between $40 \%$ and $80 \%$ of its main axis). Clusters were classified as "Cylindrical" (O.I.V. shape=1), "Conical" (O.I.V. shape=2) or "Funnel-shaped" (O.I.V.

This article is protected by copyright. All rights reserved. 
shape=3). Cylindrical clusters (Figure $3 \mathrm{~A}$ ) have a similar section along all this region, whereas the conical (Figure 3B) and the funnel-shaped clusters (Figure $3 \mathrm{C}$ ) display a width that is greater at $40 \%$ of their length than at $80 \%$. In conical clusters the narrowing occurs progressively, whereas the funnel-shaped clusters are characterized by a rapid narrowing in the upper part of this region, ending in a cylindrical section.

\section{Statistical analysis}

Evaluation of the accuracy and agreement between manual and 2D image-based methods

Pearson coefficients $(r)$ were calculated to evaluate correlations between the manual and the novel systems. As $r$ measures the strength of the relation between two variables but not their similitude, the Bland and Altman ${ }^{29}$ approach was used to test their accuracy by plotting the mean of the values obtained between both methods $(\mu)$ versus their difference $(d)$. The $95 \%$ confidence interval was calculated as $\mu_{\mathrm{d}} \pm 1.96 \sigma_{\mathrm{d}}{ }^{29}$, where $\mu_{\mathrm{d}}$ and $\sigma_{\mathrm{d}}$ indicate the mean and the standard deviation of the differences between the two approaches, respectively. Accordingly, the mean value represents the systematic bias between both methods, whereas the limits of agreement of the confidence interval evaluate how precise the two systems are along the respective ranges of variation.

\section{Evaluation of cluster shape and compactness using variables from image-based methods}

One-way ANOVA with Fisher's LSD post-hoc tests $(P \leq 0.05)$ were used to compare $C_{1}$ and $C_{2}$ mean values in the different cluster shape classes. Moreover, $C_{1}$ and $C_{2}$ were used as input variables to build a decision tree for the classification of clusters according to their shape, using the CART (classification and regression tree) approach $^{30}$ with the default settings. In this approach, a series of sequential nodes and critical cut-off values are automatically calculated to classify each cluster in a series of subgroups.

The correlation between the visual value of compactness and different objective variables was evaluated by means of Kendall's $\tau_{b}$ coefficients. These variables were also compared with the

This article is protected by copyright. All rights reserved. 
continuous value of compactness given by $\mathrm{Cl}-12$, using Pearson coefficients. One-way ANOVA with Fisher's LSD post-hoc tests were used to compare the mean values of certain variables (or derived ratios) for the different groups of visual compactness. Given the low number of very loose clusters in our sample, this class was not included in the analyses. A simple linear regression model based on a set of independent predictors was tested and validated, the mean visual value of compactness being considered as the continuous dependent variable. For this purpose, the dataset was subdivided into two groups of 40 clusters, each with five randomly chosen clusters per variety. The first set was used for the construction of the statistical model, whereas the second one was used for its validation. The coefficient of determination $R^{2}$ was used to ascertain the percentage of trait variance explained by the model. Root mean square error (RMSE) values between manual and predicted values were used for error estimation ${ }^{31}$.

All calculations were performed using SPSS v.22.0 (IBM, Chicago, IL, USA).

\section{RESULTS AND DISCUSSION}

Grapevine cluster morphology is commonly used for the characterization of grapevine germplasm ${ }^{32}$, it is routinely evaluated for the selection of elite cultivars in breeding ${ }^{33}$, and it affects consumers' perception ${ }^{1}$. Moreover, and as for other agricultural products, obtaining information about the morphology of the grapevine cluster is relevant for the modeling, design and optimization of industrial processes ${ }^{2,15,34}$. Some traditional descriptors proposed by international organizations, like the O.I.V., are subjective and/or qualitative, which hinders some studies and industrial applications that need an accurate and fine evaluation ${ }^{10-12}$. Recent advances in image processing have proven to improve (in terms of accuracy and time) the measurement of different morphological attributes in different foodstuffs and plant materials. In this work, 2D and 3D technologies have been assessed for the automated estimation of different morphological attributes of the grapevine cluster.

This article is protected by copyright. All rights reserved. 


\section{Determination of cluster size and elongation}

Cluster size was estimated through the evaluation of its maximal length and width, and cluster elongation was calculated as the ratio between them. We obtained strong significant correlations $(P \leq 0.001)$ between the manual and the image-based methods for cluster length $(r=0.959$; Supporting Figure 1A), cluster width ( $r=0.861$; Supporting Figure $1 \mathrm{~B})$ and cluster elongation ( $r=0.852$; Supporting Figure 1C). The latest variable ranged from 1.01 (a cluster of the wine cultivar Cabernet Franc) to 2.84 (a cluster of the table cultivar Ruby Seedless) in our dataset.

The Bland and Altman ${ }^{29}$ approach showed that the values obtained by means of the $2 \mathrm{D}$ image method for both cluster length (Supporting Figure 2A) and width (Supporting Figure 2B) closely matched the manual measurements, with a mean value close to $0\left(\mu_{\mathrm{d}}=-0.02\right.$ and $-0.58 \mathrm{~cm}$ for cluster length and cluster width, respectively). Moreover, the confidence intervals were small enough to sustain that this novel method can substitute the traditional one (Supporting Figures $2 \mathrm{~A}$ and $2 \mathrm{~B}$ ). Regarding cluster elongation (Supporting Figure $2 \mathrm{C}$ ), the mean difference between both approaches was 0.076 , and the $95 \%$ confidence interval ranged from 0.444 to 0.292. The differences between the ratios calculated from manual and $2 \mathrm{D}$ images were well distributed within the interval limits, and no bias was observed along the whole $x$-axis (Supporting Figure $2 \mathrm{C}$ ). Altogether, our results suggest that the size and the elongation of the cluster can be accurately measured by the analysis of $2 \mathrm{D}$ images, thereby replacing timeconsuming traditional systems.

\section{Evaluation of cluster shape from image-based technologies}

Cluster shape is included among the traits used to characterize and identify different grapevine cultivars $^{32}$. O.I.V. descriptor № 208 classifies clusters into three morphotypes according to the shape of the region between $3 / 5$ and $4 / 5(40-80 \%)$ of the main axis of the cluster. The conicity calculated considering these extreme points $\left(C_{1}\right.$, Eq.5) allowed the cylindrical clusters

This article is protected by copyright. All rights reserved. 
(Supporting Figure 3A) to be discriminated from the other morphotypes. As expected, they presented lower values for this ratio when compared to the conical and the funnel-shaped clusters, which are wider in the upper part than in the lower part of the cluster (Figure 3). Similarly, the conicity calculated using $\mathrm{Wi}_{2 \mathrm{D}}$ and $\mathrm{Wi}_{2 \mathrm{O}}\left(\mathrm{C}_{2}\right.$, Eq.6) could differentiate the conical clusters from the other two morphotypes (Supporting Figure 3B), which present a similar morphology in the lower section (Figure 3).

The decision tree constructed on the basis of $C_{1}$ and $C_{2}$ values showed that $C_{1}$ was the most determining predictor, with a cut-off value of 0.470 . When this variable was used in the first step of the classification in the decision tree, $76 \%$ of the clusters included in node 1 had been visually classified as cylindrical (Figure 4). In a second step, the 51 remaining clusters were then categorized according to their $C_{2}$ value (cut-off $=0.249$ ), with the funnel-shaped clusters having the lowest values. Considering both steps, 19 out of 24 (79.2\%) conical clusters were correctly classified (node 4, Figure 4), while node 3 included a majority of funnel-shaped clusters (66.7\%). Nonetheless, most clusters visually classified as funnel-shaped (and an important number of clusters visually categorized as cylindrical) were included in node 4 . This misclassification was probably caused by the several difficulties existing in the visual classification of cluster shape. First, there are no clear borders between the different classes of cluster shape, and certain clusters with intermediate shapes can be assigned to different categories. Second, the approach proposed by the O.I.V. evaluates a short region of the cluster $(40-80 \%)$, and its visual delimitation can be a complicated task for the judge, whose opinion can be biased by the global morphology of the cluster or its size. Thus, subjectivity may be high in visual classification, making it difficult to obtain accurate reference data. The method proposed here maintains the spirit of the O.I.V. descriptor, but avoids the problems of subjectivity. It uses variables measured at the exact points defined for cluster shape evaluation, and sets a series of cut-off values for the individual assignment to the different shape classes. The stated cut-off values could need fine tuning by including more samples, but

This article is protected by copyright. All rights reserved. 
in general terms the analysis of $2 \mathrm{D}$ images provides relevant and precise information for the assessment of cluster shape.

\section{Determination of the morphological volume of the cluster}

Two novel methods have been tested for the estimation of the morphological volume of the cluster: (I) direct 3D scanning, and (II) a geometric reconstruction using variables obtained from the 2D image analysis (Figures $1 B$ and 1D). Both methods showed a high level of significant correlation $(P \leq 0.001)$ to the manual value $(r=0.956$ and 0.953 for the $2 \mathrm{D}$ and $3 \mathrm{D}$ methods, respectively), and a coefficient of determination $\left(R^{2}\right)$ of 0.914 for the 2D system and 0.908 for the 3D approach. These results initially suggested that both methods could be used for the accurate estimation of the trait. Nonetheless, the Bland and Altman ${ }^{29}$ approach (Figures 5A and 5B) revealed a systematic underestimation for the 3D system $\left(\mu_{\mathrm{d}}=-169.20 \mathrm{~mL}\right)$. Moreover, this system was characterized by a wide error (95\% confidence interval limits: 31.02 and $-369.42 \mathrm{~mL}$ ), and a systematic bias dependent on cluster size: the underestimation of the morphological volume was greater as the volume of the cluster increased.

In our sample, the bigger clusters were those of the table grape cultivar Ruby Seedless, which presented a loose appearance characterized by the presence of numerous cavities in their morphology. The volume of such cavities was captured by the manual system and by the geometric reconstruction calculated from 2D image analysis, leading to the similarity of both values. By contrast, the 3D method excluded a fraction of that 'empty' volume of the closed mesh (Figure 2B), thus generating an underestimation of the morphological volume if compared to the other two methods. The 3D method released an intermediate value between the actual and the morphological volumes in loose clusters, whereas it released a more accurate value for compact clusters, since they have a smaller number of cavities. Hence, in a highly diverse set of clusters, the $2 \mathrm{D}$ approach seems to be more appropriate than the 3D system for the evaluation of the morphological volume. Moreover, the proposed geometric

This article is protected by copyright. All rights reserved. 
reconstruction fits the variable cluster shapes. Previous measurements, like the conical estimation proposed by Shavrukov, Dry and Thomas ${ }^{14}$, did not represent the different morphotypes that can be found in the grapevine in a realistic way. In this work, the grapevine cluster has been divided into four sections whose volumes have been independently calculated, leading to a simple approach for the evaluation of the morphological volume of the cluster.

\section{Evaluation of cluster compactness from image-based technologies}

Cubero, Diago, Blasco, Tardaguila, Prats-Montalbán, Ibáñez, Tello and Aleixos ${ }^{24}$ have recently shown that the analysis of $2 \mathrm{D}$ images allows the determination of some compactness-related attributes that cannot be assessed by hand, although they can be quite useful for the automated evaluation of this feature. In our work, the percentage of pixels of the $2 \mathrm{D}$ image not occupied by berries [hence corresponding to parts of the rachis or empty holes, AR $(\%)_{2 \mathrm{D}}+$ $\mathrm{AH}(\%)_{2 \mathrm{D}}$ ] showed a large correlation with both the mode value of visual compactness given by the panel of judges and the objective and quantitative index $\mathrm{Cl}-12$ (Table 1).

A one-way ANOVA for AR $(\%)_{2 D}+A H(\%)_{2 D}$ revealed a statistically significant result $(P \leq 0.05)$, and Fisher's LSD post-hoc tests revealed that all classes were statistically distinct $(P \leq 0.05)$, except those from compact and very compact clusters (data not shown). According to the O.I.V. descriptor for cluster compactness, the visibility of pedicels and the occurrence of empty holes in the cluster allows a distinction to be made between very loose, loose and medium clusters, whereas compact and very compact clusters are so dense that they do not have visible pedicels/rachis or empty spaces in their structure ${ }^{9}$, thus supporting our findings. Following the O.I.V. descriptor ${ }^{9}$, these two classes differ according to the absence (compact clusters) or presence (very compact clusters) of deformed berries, which may appear as a result of the compression stresses that occur during the development of the cluster ${ }^{5}$ in clusters with a large solid volume per $\mathrm{cm}$ of rachis.

This article is protected by copyright. All rights reserved. 
To obtain an indirect and automatic estimation of such compression, we calculated the compactness index $\mathrm{Cl}-13_{2 \mathrm{D}}$ (Eq.7) using only measurements obtained from the $2 \mathrm{D}$ image analysis. This ratio relativizes the cluster morphological volume (which is close to the actual volume in tight clusters) to the squared cluster length, so it is expected to increase as cluster compactness increases. $\mathrm{Cl}-13_{2 \mathrm{D}}$ showed statistically significant coefficients of correlation with both the mode value of compactness given by the panel of judges $\left(\tau_{b}=0.591 ; P \leq 0.01\right)$, and $\mathrm{Cl}$ $12(r=0.775 ; P \leq 0.01)$. A one-way ANOVA for $\mathrm{Cl}^{-13_{2 D}}$ revealed a statistically significant result $(P \leq 0.05)$, all the groups of compactness being statistically distinct (Fisher's LSD post-hoc test, $P \leq 0.05$, data not shown).

$\mathrm{AR}(\%)_{2 \mathrm{D}}+\mathrm{AH}(\%)_{2 \mathrm{D}}$ and $\mathrm{Cl}-13_{2 \mathrm{D}}$ represent attributes that are highly related to cluster compactness, and measure different cluster compactness-related features. Those variables are significantly inter-correlated in our set of clusters $(r=-0.419 ; P \leq 0.01)$, revealing that they explain a common part of the morphological variation. This negative correlation is not unexpected, since clusters with more volume per $\mathrm{cm}$ of rachis (high values for $\mathrm{Cl}-13_{2 \mathrm{D}}$ ) usually have fewer visible pedicels and empty holes [low values for AR $(\%)_{2 \mathrm{D}}+\mathrm{AH}(\%)_{2 \mathrm{D}}$ ], and vice versa.

Considering that $\mathrm{AR}(\%)_{2 \mathrm{D}}+\mathrm{AH}(\%)_{2 \mathrm{D}}$ and $\mathrm{Cl}-13_{2 \mathrm{D}}$ also bear independent information about cluster compactness, they were used as predictive variables to construct a regression model (Eq.10). The analysis of the standardized regression coefficients $(\beta)$ of both variables in the model indicated that the predictive weight of $A R(\%)_{2 D}+A H(\%)_{2 D}(|\beta|=0.664)$ is considerably higher than that of $\mathrm{Cl}-13_{2 \mathrm{D}}(|\beta|=0.343)$. The model showed a predictive capability $\left(R^{2}\right)$ of $84.5 \%(P \leq 0.01)$ for the training set of 40 clusters, and $71.1 \%(P \leq 0.01)$ when applied to the validation set. These values are similar to those reported by Ivorra, Sánchez, Camarasa, Diago and Tardáguila ${ }^{25}\left(R^{2}=80.8 \%\right)$ and Cubero, Diago, Blasco, Tardaguila, Prats-Montalbán, Ibáñez, Tello and Aleixos ${ }^{24}\left(R^{2}=85.3 \%\right)$. Moreover, we found similar low values of RMSE in both subsets of clusters ( 0.79 and 1.12 , respectively), thus indicating that the model performs well

This article is protected by copyright. All rights reserved. 
not only for the set of clusters used for its construction (training set), but also for a different sample (validation set).

Comp $=5.077-0.497 \times[\mathrm{AR}(\%)+\mathrm{AH}(\%)]+1.596 \times \frac{\mathrm{MVO}_{2 \mathrm{D}}(\mathrm{mL})}{\left[\mathrm{Le}_{2 \mathrm{D}(\mathrm{cm})}\right]^{2}}$

The predicted value of cluster compactness showed a high correlation with the visual one in both subsets of clusters $(r=0.924$ for the training set and $r=0.843$ for the validation set; $P \leq 0.01$ ) (Figure 6). Considering the complexity of the trait, and the use of a visual, subjective, and qualitative value as a reference, it is acceptable to find up to a one-class difference between the visual and the predicted values of compactness ${ }^{10}$. In our model, all the predicted values (but one) fall within this range of variation (Figure 6). Moreover, we observed a high level of linear correlation between the predicted value and both the visual value of compactness $\left(\tau_{\mathrm{b}}=0.721 ; P \leq 0.01\right)$ and the objective index $\mathrm{Cl}-12(r=0.878 ; P \leq 0.01)$ for the whole set of clusters $(n=80)$. Coefficients were higher than those obtained individually for the predictors included in the model (Figure 7). Moreover, a one-way ANOVA followed by a Fisher's LSD post-hoc test showed significant differences $(P \leq 0.05)$ for the model-predicted values among the different classes of visual compactness (Supporting Figure 4). In comparison to previous works ${ }^{10,24,25}$, the proposed model has the advantage of involving a low number of variables $\left(A R_{2 D}, A H_{2 D}, L_{2 D}, W i 25_{2 D}, W_{i 50_{2 D}}\right.$, and $\left.W i 75_{2 D}\right)$, which can be obtained automatically from 2D images with no long computation times. Altogether, our results suggest that cluster compactness can be evaluated in a fast, automated and accurate way through the analysis of $2 \mathrm{D}$ images.

\section{CONCLUSIONS}

In this work, different cluster morphological attributes with an impact on crop yield and quality have been measured automatically through the application of novel 2D and 3D image-based technologies. 2D image processing has provided a simple, accurate and objective framework to estimate cluster size and elongation. This system provides similar values to those obtained by

This article is protected by copyright. All rights reserved. 
means of traditional systems, but having the advantage of the short period of time needed for their high throughput characterization. Some insights for the measurement of cluster shape are given, and the evaluation of the conicity of the cluster at its central part emerges as a promising starting point. The estimation of the morphological volume of the cluster through direct 3D scanning was faulty, especially for the loosest clusters. Hence, the 2D approach proposed in this work is more appropriate when evaluating this trait in a highly diverse set of clusters. Lastly, we propose a model for cluster compactness estimation based on the automatic evaluation of two cluster attributes related to this trait (visibility of the pedicels and/or empty holes in the cluster, and the compaction of the berries), which can be estimated from the analysis of 2D images. Its high predictive capability suggests the usefulness of the model for the objective and automatic evaluation of this complex trait. The advances presented here can be applied in different contexts, including sorting tables of table grapes and in wineries for the classification of clusters prior to winemaking. They may also be used in breeding programs focused on generating new elite cultivars or clones, and in genetic studies aimed at identifying the underlying genetics of grapevine cluster morphology.

\section{ACKNOWLEDGEMENTS}

We acknowledge R. Aguirrezábal, B. Larreina and M.I. Montemayor for their technical assistance. This work was supported by the Spanish Ministerio de Economía y Competitividad (MINECO) through project AGL2010-15694 and the Instituto Nacional de Investigación y Tecnología Agraria y Alimentaria (INIA) through projects RTA2012-00062-C04-01 and RTA201200062-C04-03 with the support of European FEDER funds. J. Tello acknowledges the MINECO for his predoctoral fellowship (BES-2011-047041).

\section{REFERENCES}

1. Dragincic J, Korac $\mathrm{N}$ and Blagojevic B, Group multi-criteria decision making (GMCDM) approach for selecting the most suitable table grape variety intended for organic viticulture. Comput Electron Agric 111:194-202 (2015).

This article is protected by copyright. All rights reserved. 
2. Carmona MJ, Chaib J, Martínez-Zapater JM and Thomas MR, A molecular genetic perspective of reproductive development in grapevine. J Exp Biol 59:2579-2596 (2008).

3. Intrigliolo DS, Llacer E, Revert J, Esteve MD, Climent MD, Palau D and Gómez I, Early defoliation reduces cluster compactness and improves grape composition in Mandó, an autochthonous cultivar of Vitis vinifera from southeastern Spain. Sci Hort 167:71-75 (2014).

4. Tello J, Aguirrezábal R, Hernaiz S, Larreina B, Montemayor MI, Vaquero E and Ibáñez J, Multicultivar and multivariate study of the natural variation for grapevine bunch compactness. Aust J Grape Wine Res 21:277-289 (2015).

5. Vail ME and Marois JJ, Grape cluster architecture and the susceptibility of berries to Botrytis cinerea. Phytopathology 81:188-191 (1991).

6. Fermaud M, Cultivar susceptibility of grape berry clusters to larvae of Lobesia botrana (Lepidoptera: Tortricidae). J Econ Entomol 91:974-980 (1998).

7. May $\mathrm{P}$, From bud to berry, with special reference to inflorescence and bunch morphology in Vitis vinifera L. Aust J Grape Wine Res 6:82-98 (2000).

8. Molitor D, Behr M, Hoffman L and Evers D, Impact of grape cluster division on cluster morphology and bunch rot epidemic. Am J Enol Vitic 63:508-514 (2012).

9. O.I.V., OIV descriptor list for grape varieties and Vitis species. Organisation Internationale de la Vigne et du Vin, Paris (2007).

10. Tello $\mathrm{J}$ and Ibáñez J, Evaluation of indexes for the quantitative and objective estimation of grapevine bunch compactness. Vitis 53:9-16 (2014).

11. Kicherer A, Roscher R, Herzog K, Simon S, Förstner W and Topfer R, BAT (Berry Analysis Tool): A high-throughput image interpretation tool to acquire the number, diameter, and volume of grapevine berries. Vitis 52:129-135 (2013).

12. Roscher R, Herzog K, Kunkel A, Kicherer A, Topfer R and Förstner W, Automated image analysis framework for high-throughput determination of grapevine berry sizes using conditional random fields. Comput Electron Agric 100:148-158 (2014).

13. Houel C, Martin-Magniette ML, Nicolas SD, Lacombe T, Le Cunff L, Franck D, Torregrosa L, Conejero G, Lalet S, This $P$ and Adam-Blondon AF, Genetic variability of berry size in the grapevine (Vitis vinifera L.). Aust J Grape Wine Res 19:208-220 (2013).

14. Shavrukov YN, Dry IB and Thomas MR, Inflorescence and bunch architecture development in Vitis vinifera L. Aust J Grape Wine Res 10:116-124 (2004).

15. Sepahi A, Estimating cluster compactness in Yaghouti grapes. Vitis 19:81-90 (1980).

16. Ferreira JHS and Marais PG, Effect of rootstock cultivar, pruning method and crop load on Botrytis cinerea rot of Vitis vinifera cv. Chenin blanc grapes. S Afr J Enol Vitic 8:41-44 (1987).

17. Moreda GP, Ortiz-Cañavate J, García-Ramos FJ and Ruiz-Altisent M, Non-destructive technologies for fruit and vegetable size determination - a review. J Food Eng 92:119-136 (2009).

18. Cubero S, Aleixos N, Moltó E, Gómez-Sanchis J and Blasco J, Advances in machine vision applications for automatic inspection and quality evaluation of fruits and vegetables. Food Bioprocess Tech 4:487-504 (2011).

19. Lorente D, Aleixos N, Gómez-Sanchis J, Cubero S, García-Navarrete OL and Blasco J, Recent advances and applications of hyperspectral imaging for fruit and vegetable quality assessment. Food Bioprocess Tech 6:1121-1142 (2012).

20. Zhang B, Huang W, Li J, Zhao C, Fan S, Wu J and Liu C, Principles, developments and applications of computer vision for external quality inspection of fruits and vegetables. Food Res Int 62:326-343 (2014).

21. Tardaguila J, Diago MP, Millán B, Blasco J, Cubero S and Aleixos N, Applications of computer vision techniques to assess canopy features, cluster morphology and berry size, in $I$ International workshop on vineyard mechanization and grape and wine quality, Ed, Piacenza (2012).

This article is protected by copyright. All rights reserved. 
22. Diago MP, Tardaguila J, Aleixos N, Millán B, Prats-Montalbán JM, Cubero S and Blasco J, Assessment of cluster yield components by image analysis. J Sci Food Agr 95:1274-1282 (2015).

23. Cubero S, Diago MP, Blasco J, Tardaguila J, Millán B and Aleixos N, A new method for pedicel/peduncle detection and size assessment of grapevine berries and other fruits by image analysis. Biosyst Eng 117:62-72 (2014).

24. Cubero S, Diago MP, Blasco J, Tardaguila J, Prats-Montalbán JM, Ibáñez J, Tello J and Aleixos N, A new method for assessment of bunch compactness using automated image analysis. Aust J Grape Wine Res 21:101-109 (2015).

25. Ivorra E, Sánchez AJ, Camarasa JG, Diago MP and Tardáguila J, Assessment of grape cluster yield components based on 3D descriptors using stereo vision. Food Control 50:273-282 (2015).

26. Herrero-Huerta M, González-Aguilera D, Rodríguez-Gonzalvez $\mathrm{P}$ and Hernández-López D, Vineyard yield estimation by automatic 3D bunch modelling in field conditions. Comput Electron Agric 110:17-26 (2015).

27. Schöler $\mathrm{F}$ and Steinhage $\mathrm{V}$, Automated 3D reconstruction of grape cluster architecture from sensor data for efficient phenotyping. Comput Electron Agric 114:163-177 (2015).

28. Omid $M$, Khojastehnazhand $M$ and Tabatabaeefar $A$, Estimating volume and mass of citrus fruits by image processing technique. J Food Eng 100:315-321 (2010).

29. Bland JM and Altman DG, Statistical mehods for assessing agreement between two methods of clinical measurement. Lancet 327:307-310 (1986).

30. Breiman L, Freidman J, Olshen R and Stone C, Classification and regression trees. Wadsworth Statistics (1984).

31. Paulus $\mathrm{S}$, Behmann J, Mahlein A-K, Plümer L and Kuhlmann $\mathrm{H}$, Low-cost 3D systems: suitable tools for plant phenotyping. Sensors 14:3001-3018 (2014).

32. Maul E, Sudharma kN, Kecke S, Marx G, Muller C, Audeguin L, Boselli M, Boursiquot JM, Bucchetti B, Cabello F, Carraro R, Crespan M, de Andrés MT, Eiras Dias J, Ekhvaia J, Gaforio L, Gardiman M, Grando S, Gyropoulos D, Jandurova O, Kiss E, Kontic J, Kozma P, Lacombe T, Laucou V, Legrand D, Maghradze D, Marinoni D, Maletic E, Moreira F, Muñoz-Organero G, Nakhurtsrishvili G, Pejic I, Peterlunger E, Pitsoli D, Pospisilova D, Preiner D, Raimondi S, Regner F, Savin G, Savvides S, Schneider A, Sereno C, Simon S, Staraz M, Zulini L, Bacilieri R and This P, The European Vitis Database (www.eu-vitis.de) - a technical innovation through an online uploading and interactive modification system. Vitis 51:79-85 (2012).

33. Reisch Bl, Owens $\mathrm{CL}$ and Cousins PS, Grape, in Fruit Breeding, Handbook of Plant Breeding, ed. by Badenes ML and Byrne DH. Springer, New York, pp 225-262 (2012).

34. Nelson KE, Ahmedullah M and Mitchell FG, Effect of container and packing methods on injury and transpiration of table grapes. Am J Enol Vitic 21:101-108 (1970).

This article is protected by copyright. All rights reserved. 
Table 1. Coefficients of correlation between cluster attributes obtained by image-based technologies and (i) the visual mode value of compactness stated by the judges panel $\left(\tau_{\mathrm{b}}\right)$, and (ii) the quantitative value of compactness calculated according to $\mathrm{Cl}-12$ index proposed by Tello and Ibáñez ${ }^{10}(r)$. NS: not significant; *: significant at 0.05 level; **: significant at 0.01 level.

\begin{tabular}{lll}
\hline & $\begin{array}{l}\text { Visual } \\
\text { compactness }\end{array}$ & $\begin{array}{l}\text { Compactness } \\
\text { index Cl-12 }\end{array}$ \\
\hline $\mathrm{AR}(\%)_{2 \mathrm{D}}+\mathrm{AH}(\%)_{2 \mathrm{D}}$ & $-0.672^{* *}$ & $-0.730^{* *}$ \\
$\mathrm{Le}_{2 \mathrm{D}}(\mathrm{cm})$ & $-0.257^{* *}$ & $-0.234^{*}$ \\
$\mathrm{Wi}_{2 \mathrm{D}}(\mathrm{cm})$ & $\mathrm{NS}$ & $0.320^{* *}$ \\
$\mathrm{Wi}_{2 \mathrm{D}}(\mathrm{cm})$ & $\mathrm{NS}$ & $0.346^{* *}$ \\
$\mathrm{Wi}_{2 \mathrm{D}}(\mathrm{cm})$ & $\mathrm{NS}$ & $\mathrm{NS}$ \\
$\mathrm{Wi50}_{2 \mathrm{D}}(\mathrm{cm})$ & $0.230^{* *}$ & $0.516^{* *}$ \\
$\mathrm{Wi60}_{2 \mathrm{D}}(\mathrm{cm})$ & $0.402^{* *}$ & $0.472^{* *}$ \\
$\mathrm{Wi75}_{2 \mathrm{D}}(\mathrm{cm})$ & $0.581^{* *}$ & $0.765^{* *}$ \\
$\mathrm{Wi80}_{2 \mathrm{D}}(\mathrm{cm})$ & $0.614^{* *}$ & $0.720^{* *}$ \\
\hline
\end{tabular}

This article is protected by copyright. All rights reserved. 
Figure Captions

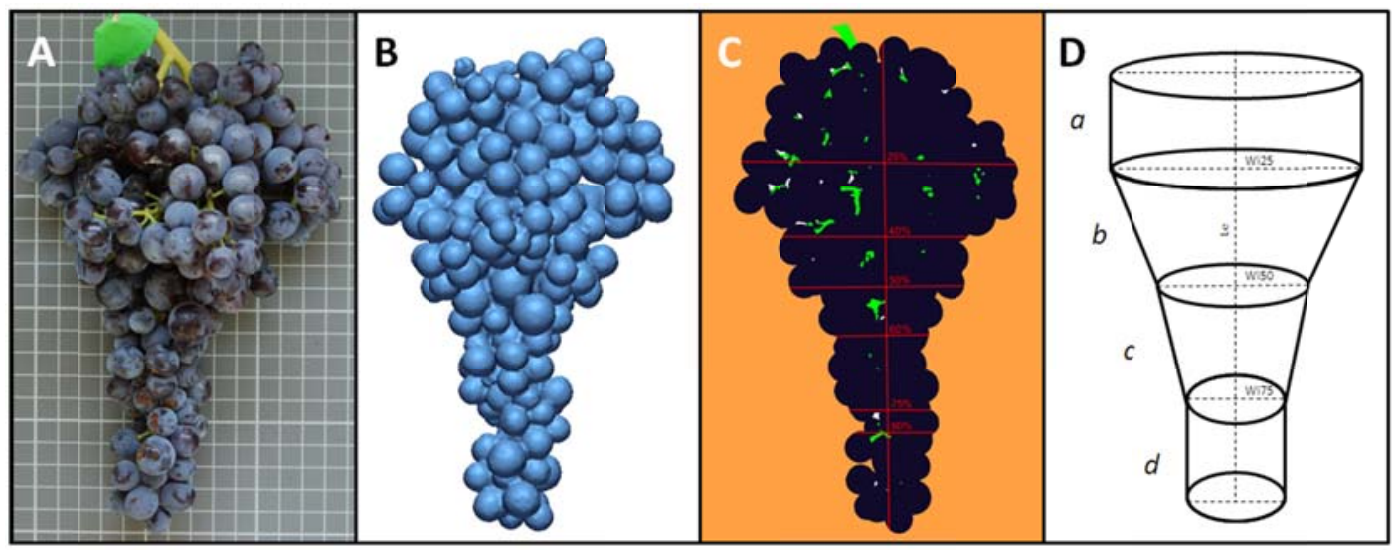

Figure 1. Example of a grapevine cluster (cv. Derechero de Muniesa) used for direct characterization (A), reconstruction of the cluster structure after 3D scanning (B), segmentation of the 2D image for the measurement of different cluster attributes (C), and geometric reconstruction of the morphological volume into four sections $(a, b, c$ and $d)$ (D). In C, black, green and white regions refer to areas covered by berries, rachis and empty holes, respectively, and red lines indicate cluster length and width at $25,40,50,60,75$ and $80 \%$ of the main axis.

This article is protected by copyright. All rights reserved. 

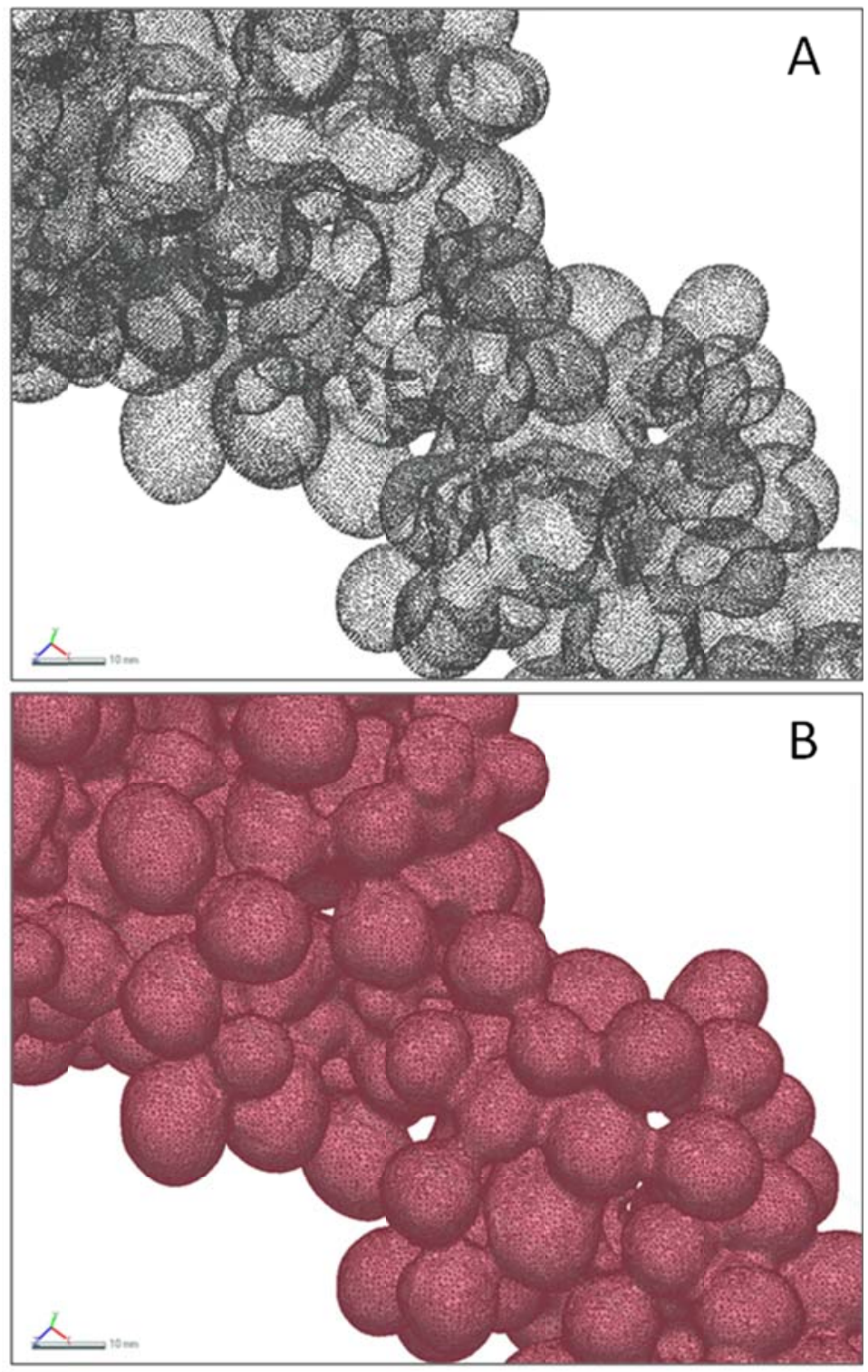

Figure 2. Detail of the cloud of datapoints created in the central part of a grapevine cluster (cv.

Ruby Seedless) by means of the 3D scanner (A). In (B) the same region after computing the mesh connecting such datapoints as shaded poly-faces is shown.

This article is protected by copyright. All rights reserved. 

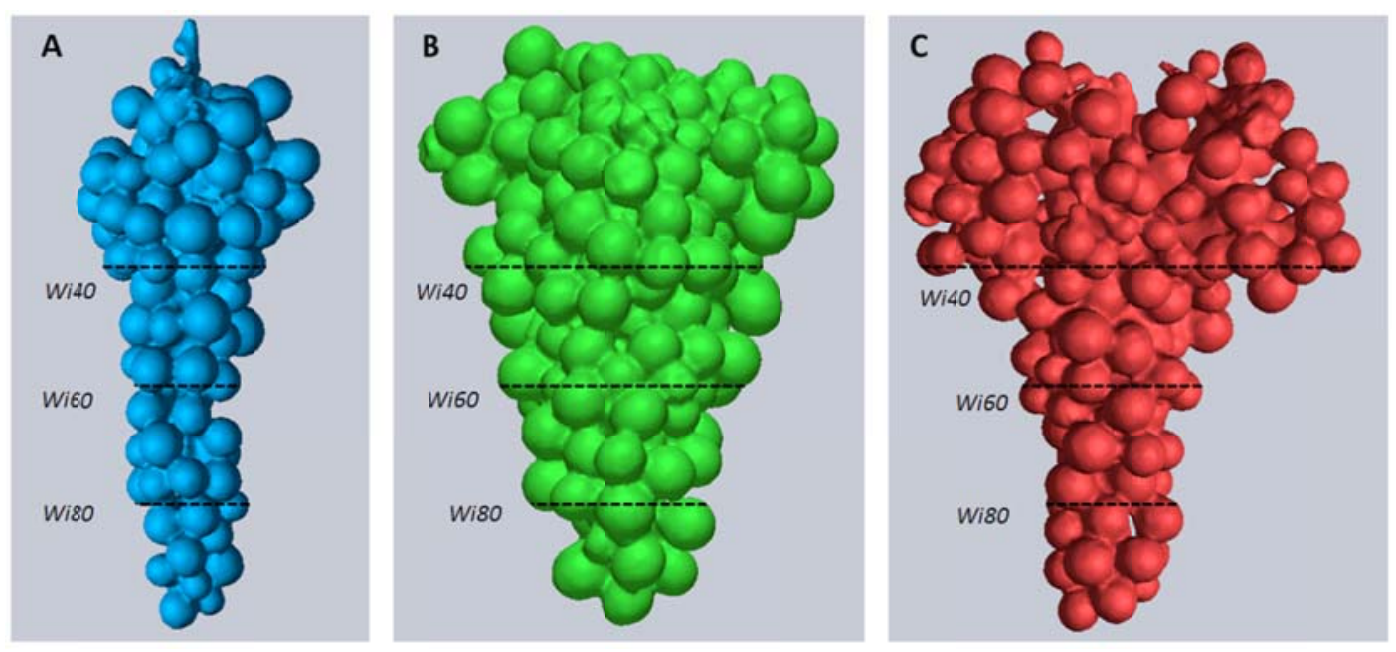

Figure 3. Examples of cylindrical (A), conical (B) and funnel-shaped (C) clusters according to the O.I.V. descriptor №208. Broken lines indicate positions at 40,60 and $80 \%$ of the main axis. Images in A, B and C, correspond to clusters of the cultivars Aramon, Monastrell and Cabernet Franc, respectively.

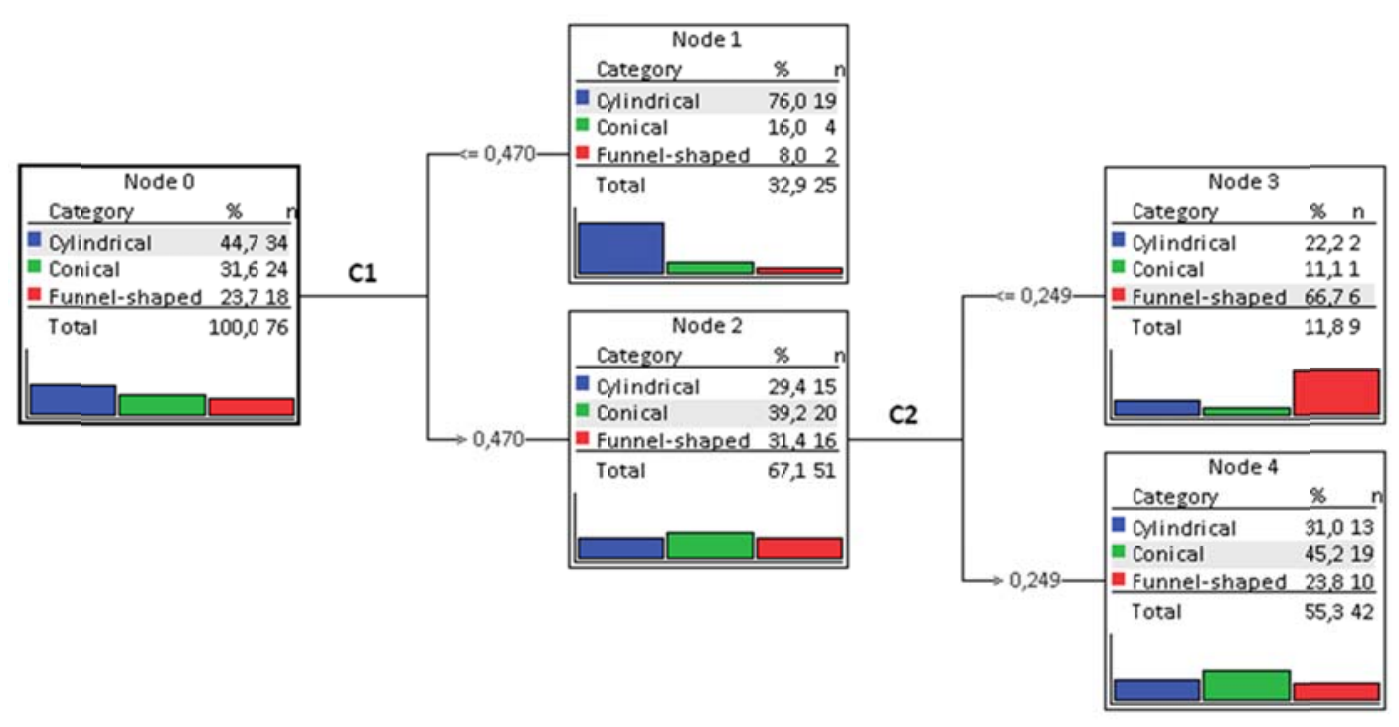

Figure 4. Decision tree for classifying grapevine clusters according to the three shapes proposed by the O.I.V. descriptor №208 ${ }^{9}$ (cylindrical, conical and funnel-shaped) on the basis of two conicity measurements $\left(C_{1}\right.$ and $\left.C_{2}\right)$. $C_{1}$ and $C_{2}$ refer to equations 5 and 6 , respectively.

This article is protected by copyright. All rights reserved. 


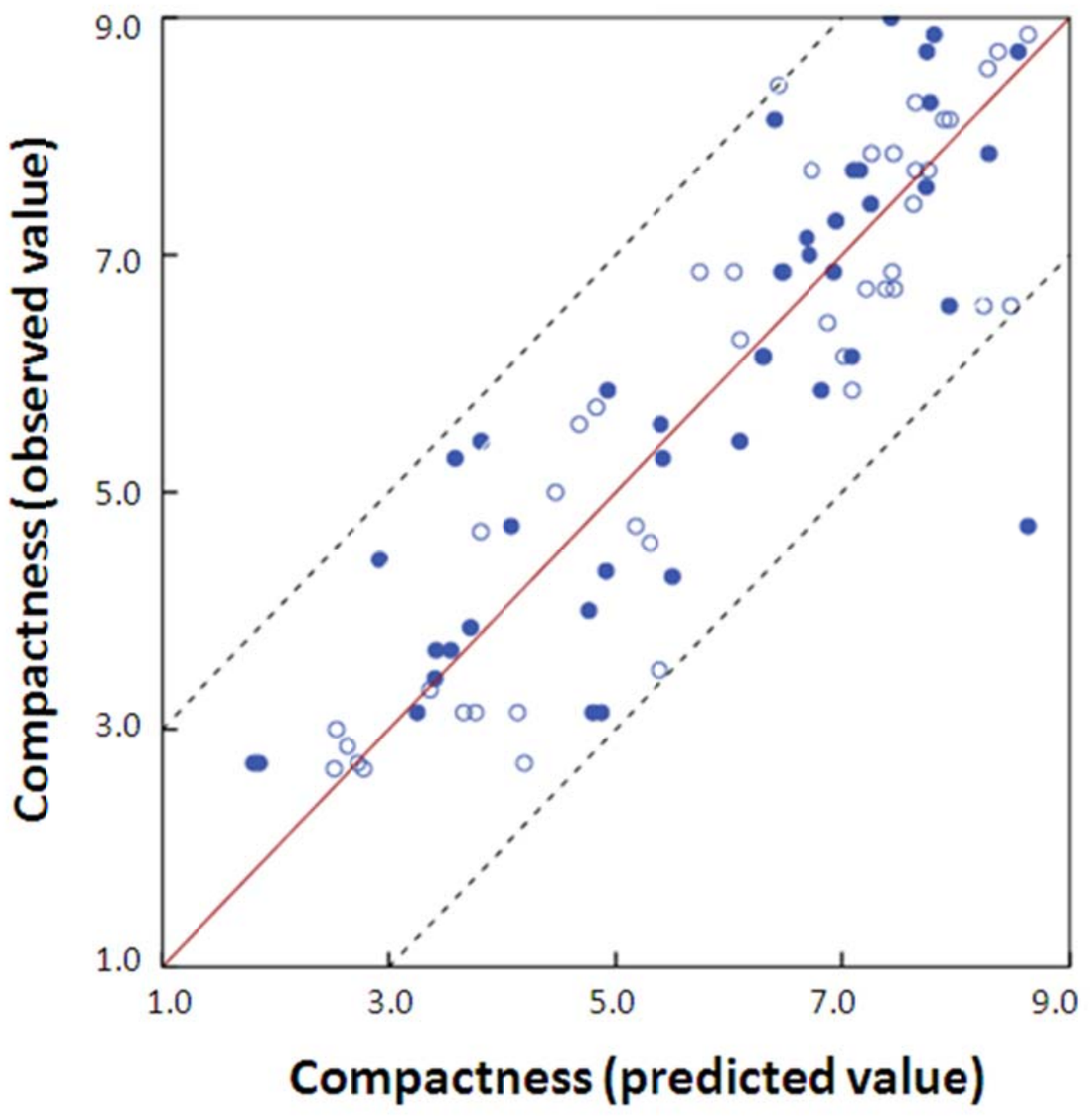

Figure 6. Observed versus predicted values of compactness obtained by the regression model in the training (empty circles) and the validation (filled circles) subset of clusters. The identity line $(y=x)$ is shown as a red line. Dashed lines indicate the tolerated variation in one category of compactness with respect the line of equality.

This article is protected by copyright. All rights reserved. 


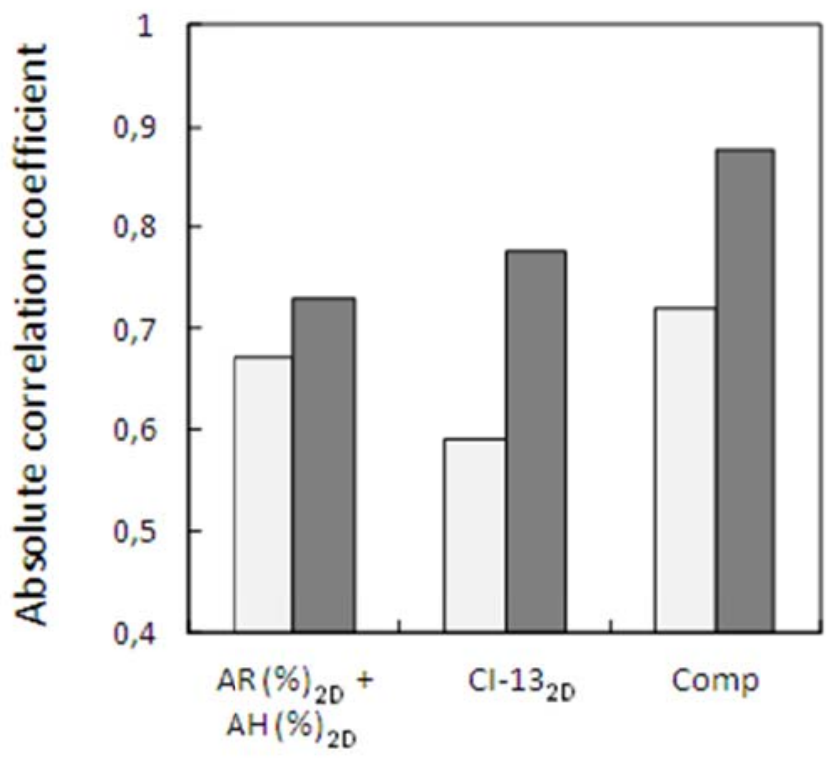

Figure 7. Absolute coefficients of correlation obtained between the visual mode value of compactness stated by the judges panel (in white; $\tau_{\mathrm{b}}$ ) or the quantitative value of compactness calculated according to $\mathrm{Cl}-12$ Tello and Ibáñez ${ }^{10}$ (in grey; $r$ ) and three automatic methods of evaluation of cluster compactness: (i) percentage of image occupied by empty holes or stem (AR $\left.(\%)_{2 \mathrm{D}}+\mathrm{AH}(\%)_{2 \mathrm{D}}\right)$, (ii) the $\mathrm{Cl}-13_{2 \mathrm{D}}$ index, and (iii) the model constructed through their combination (Comp)].

This article is protected by copyright. All rights reserved. 